\title{
Motivational and Self-Regulated Learning Components of Classroom Academic Performance
}

\author{
Paul R. Pintrich and Elisabeth V. De Groot \\ School of Education \\ University of Michigan \\ Ann Arbor, Michigan
}

\begin{abstract}
A correlational study examined relationships between motivational orientation, self-regulated learning, and classroom academic performance for 173 seventh graders from eight science and seven English classes. A self-report measure of student self-efficacy, intrinsic value, test anxiety, self-regulation, and use of learning strategies was administered, and performance data were obtained from work on classroom assignments. Self-efficacy and intrinsic value were positively related to cognitive engagement and performance. Regression analyses revealed that, depending on the outcome measure, self-regulation, self-efficacy, and test anxiety emerged as the best predictors of performance. Intrinsic value did not have a direct influence on performance but was strongly related to self-regulation and cognitive strategy use, regardless of prior achievement level. The implications of individual differences in motivational orientation for cognitive engagement and self-regulation in the classroom are discussed.
\end{abstract}

Self-regulation of cognition and behavior is an important aspect of student learning and academic performance in the classroom context (Corno \& Mandinach, 1983; Corno \& Rohrkemper, 1985). There are a variety of definitions of selfregulated learning, but three components seem especially important for classroom performance. First, self-regulated learning includes students' metacognitive strategies for planning, monitoring, and modifying their cognition (e.g., Brown, Bransford, Campione, \& Ferrara, 1983; Corno, 1986; Zimmerman \& Pons, 1986, 1988). Students' management and control of their effort on classroom academic tasks has been proposed as another important component. For example, capable students who persist at a difficult task or block out distractors (i.e., noisy classmates) maintain their cognitive engagement in the task, enabling them to perform better (Corno, 1986; Corno \& Rohrkemper, 1985). A third important aspect of self-regulated learning that some researchers have included in their conceptualization is the actual cognitive strategies that students use to learn, remember, and understand the material (Corno \& Mandinach, 1983; Zimmerman $\&$ Pons, 1986, 1988). Different cognitive strategies such as rehearsal, elaboration, and organizational strategies have been found to foster active cognitive engagement in learning and result in higher levels of achievement (Weinstein \& Mayer,

An earlier version of this article was presented at the American Educational Research Association convention, New Orleans, April 1988. Data collection and preparation of this article was made possible by a Spencer Fellowship from the National Academy of Education awarded to Paul R. Pintrich. The opinions expressed in this article are the authors' and do not reflect the positions or policies of the Spencer Foundation or the National Academy of Education. We express our thanks to Richard S. Newman and the reviewers for helpful comments on an earlier version of this article.

Correspondence concerning this article should be addressed to Paul R. Pintrich, School of Education, University of Michigan, Ann Arbor, Michigan 48109.
1986). These three components constituted our working definition of self-regulated learning in this study.

However, knowledge of cognitive and metacognitive strategies is usually not enough to promote student achievement; students also must be motivated to use the strategies as well as regulate their cognition and effort (Paris, Lipson, \& Wixson, 1983; Pintrich, 1988, 1989; Pintrich, Cross, Kozma, \& McKeachie, 1986). Although there are classroom situations and tasks that can foster motivation (cf., Corno \& Rohrkemper, 1985; Malone, 1981), there also is evidence to suggest that students' perceptions of the classroom as well as their individual motivational orientations and beliefs about learning are relevant to cognitive engagement and classroom performance (e.g., Ames \& Archer, 1988; Nolen, 1988). Accordingly, it is important to examine how the three components of self-regulated learning are linked to individual differences in student motivation in order to describe and understand how personal characteristics are related to students' cognitive engagement and classroom academic performance (Corno \& Snow, 1986; Snow, 1989; Weinert, 1987).

The theoretical framework for conceptualizing student motivation is an adaptation of a general expectancy-value model of motivation (cf., Eccles, 1983; Pintrich, 1988, 1989). The model proposes that there are three motivational components that may be linked to the three different components of selfregulated learning: (a) an expectancy component, which includes students' beliefs about their ability to perform a task, (b) a value component, which includes students' goals and beliefs about the importance and interest of the task, and (c) an affective component, which includes students' emotional reactions to the task. The expectancy component of student motivation has been conceptualized in a variety of ways in the motivational literature (e.g., perceived competence, selfefficacy, attributional style, and control beliefs), but the basic construct involves students' beliefs that they are able to perform the task and that they are responsible for their own performance. In this sense, the expectancy component in- 
volves students' answers to the question, "Can I do this task?" Different aspects of the expectancy component have been linked to students' metacognition, their use of cognitive strategies, and their effort management. In general, the research suggests that students who believe they are capable engage in more metacognition, use more cognitive strategies, and are more likely to persist at a task than students who do not believe they can perform the task (e.g., Fincham \& Cain, 1986; Paris \& Oka, 1986; Schunk, 1985).

The value component of student motivation involves students' goals for the task and their beliefs about the importance and interest of the task. Although this component has been conceptualized in a variety of ways (e.g., learning vs. performance goals, intrinsic vs. extrinsic orientation, task value, and intrinsic interest), this motivational component essentially concerns students' reasons for doing a task. In other words, what are students' individual answers to the question, "Why am I doing this task?" The research suggests that students with a motivational orientation involving goals of mastery, learning, and challenge, as well as beliefs that the task is interesting and important, will engage in more metacognitive activity, more cognitive strategy use, and more effective effort management (e.g., Ames \& Archer, 1988; Dweck \& Elliott, 1983; Eccles, 1983; Meece, Blumenfeld, \& Hoyle, 1988; Nolen, 1988; Paris \& Oka, 1986).

The third motivational component concerns students' affective or emotional reactions to the task. The important issue for students involves the question, "How do I feel about this task?" Again, there are a variety of affective reactions that might be relevant (e.g., anger, pride, guilt), but in a school learning context one of the most important seems to be test anxiety (Wigfield \& Eccles, 1989). Test anxiety has been shown to be related to perceptions of competence (e.g., Nicholls, 1976), but it can be theoretically and empirically distinct. Research on test anxiety has been linked to students' metacognition, cognitive strategy use, and effort management (e.g., Benjamin, McKeachie, Lin, \& Holinger, 1981; Culler \& Holahan, 1980; Tobias, 1985). Although the other two motivational components generally show simple, positive, and linear relations with the components of self-regulated learning, the results for test anxiety are not as straightforward. For example, Benjamin et al. (1981) found that although highanxious students seemed to be as effortful and persistent as low-anxious students, they appeared to be very ineffective and inefficient learners who often did not use appropriate cognitive strategies for achievement. On the other hand, other research suggests that high-anxious children are not persistent or avoid difficult tasks (Hill \& Wigfield, 1984). Accordingly, test anxiety may be related to the three components of selfregulated learning in different ways.

Previous research suggests that the expectancy and value components will be positively related to the three self-regulated learning components, whereas the research on test anxiety does not suggest such simple relations. Accordingly, one purpose of this study was to examine and clarify the empirical relations between the motivational and self-regulated learning components. In addition, because very few prior studies have included all three motivational components in their designs, a second purpose involved examining the potential interactive relations of the three motivational components on self-regulated learning components. Finally, the relations between motivation, self-regulated learning, and student performance on classroom academic tasks were examined. The focus on classroom assessments of student performance reflects a concern for ecologically valid indicators of the actual academic work that students are asked to complete in junior high classrooms (Doyle, 1983). Most students spend a great deal of classroom time on seatwork assignments, quizzes, teachermade tests, lab problems, essays, and reports rather than on standardized achievement tests (Stiggins \& Bridgeford, 1985). These assignments may not be the most psychometrically sound assessments of student academic performance, but they are closely related to the realities of instruction and learning in most classrooms (Calfee, 1985). If we are to develop models of student motivation and self-regulated learning that are relevant for much of the academic work in classrooms, then it is important to examine student performance on these types of academic tasks (cf., Doyle, 1983; Pintrich et al., 1986). Accordingly, the third purpose will provide empirical data on how motivation and self-regulated learning components may operate independently or jointly to influence student academic performance in the classroom. In summary, the three research questions were:

1. How are the three motivational components related to the components of self-regulated learning?

2. What are the interactions among the three motivational components and their relation to the self-regulated learning components?

3. How are the motivational and self-regulated learning components related to student performance on classroom academic tasks?

\section{Method}

\section{Subjects}

The sample included 173 seventh-grade students from eight science and seven English classrooms from a predominantly White, middleclass, small city school district in southeastern Michigan. There were 100 girls $(57.8 \%)$ and 73 boys $(42.2 \%)$. The mean age of the students was 12 years, 6 months in January at the end of the first semester. The school district did not track students for the science or English classes at the two junior high schools involved in this study. Accordingly, the sample of students included a range of student achievement levels.

\section{Measures}

The students responded to a self-report questionnaire (the Motivated Strategies for Learning Questionnaire-MSLQ, see Appendix) that included 56 items on student motivation, cognitive strategy use, metacognitive strategy use, and management of effort. Students were instructed to respond to the items on a 7-point Likert scale $(1=$ not at all true of $m e$ to $7=$ very true of $m e$ ) in terms of their behavior in the specific science or English class. Items were adapted from various instruments used to assess student motivation, cognitive strategy use, and metacognition (e.g., Eccles, 1983; Harter, 1981; Weinstein, Schulte, \& Palmer, 1987). Factor analysis was used to guide scale construction, resulting in exclusion of some of the items from the scales because of a lack of correlation or stable factor structure. 
Analysis of the motivational items revealed three distinct motivational factors: self-efficacy, intrinsic value, and test anxiety. The SelfEfficacy scale $(\alpha=.89)$ consisted of nine items regarding perceived competence and confidence in performance of class work (e.g., "I expect to do very well in this class," "I am sure that I can do an excellent job on the problems and tasks assigned for this class," "I know that I will be able to learn the material for this class"; cf. Eccles, 1983; Schunk, 1981). The Intrinsic Value scale $(\alpha=.87)$ was constructed by taking the mean score of the student's response to nine items concerning intrinsic interest in ("I think what we are learning in this Science class is interesting") and perceived importance of course work ("It is important for me to learn what is being taught in this English class"; cf., Eccles, 1983) as well as preference for challenge and mastery goals ("I prefer class work that is challenging so I can learn new things"; cf., Harter, 1981). Four items (e.g., "I am so nervous during a test that I cannot remember facts I have learned," "When I take a test I think about how poorly I am doing"; cf., Liebert \& Morris, 1967) concerning worry about and cognitive interference on tests were used in the Test Anxiety scale $(\alpha=.75)$.

On the basis of the results of the factor analysis, two cognitive scales were constructed: cognitive strategy use and self-regulation. The Cognitive Strategy Use scale $(\alpha=.83)$ consisted of 13 items pertaining to the use of rehearsal strategies (e.g., "When I read material for science class, I say the words over and over to myself to help me remember"), elaboration strategies such as summarizing and paraphrasing (e.g., "When I study for this English class, I put important ideas into my own words"), and organizational strategies (e.g., "I outline the chapters in my book to help me study", cf., Weinstein et al., 1987). Although metacognitive and effort management strategies were intended to be separate scales originally, factor analysis of the items did not support the construction of two different scales. One scale, labeled Self-Regulation ( $\alpha=.74$ ), was constructed from metacognitive and effort management items. The items on metacognitive strategies, such as planning, skimming, and comprehension monitoring (e.g., "I ask myself questions to make sure I know the material I have been studying," "I find that when the teacher is talking I think of other things and don't really listen to what is being said," and "I often find that I have been reading for class but don't known what it is all about," with the latter two items reflected before scale construction) were adapted from Weinstein et al. (1987) and Zimmerman and Pons (1986). Effort management strategies were adapted from Zimmerman and Pons (1986) and included students' persistence at difficult or boring tasks and working diligently (e.g., "Even when study materials are dull and uninteresting, I keep working until I finish" and "When work is hard I either give up or study only the easy parts," with the latter item reflected before scale construction).

Academic performance was measured by collecting data on student performance on actual classroom tasks and assignments. Examination of the classroom tasks and assignments for the different classrooms revealed three general categories of tasks: (a) in-class seatwork and homework, (b) quizzes and tests, and (c) essays and reports. In-class seatwork and homework usually involved answering worksheets or questions based on textbook readings. Exams and quizzes required recall or recognition of information from textbooks as in the seatwork assignments, although the students were not allowed to refer to their textbooks on the quizzes and exams. Essays and reports involved the production of original prose on topics assigned by the teacher or chosen by the student. The essays and reports often required students to use other sources (e.g., library books and encyclopedias) besides the textbook to complete the assignment. Students' performance on these three types of generic assignments were averaged over the course of the semester to generate one summary score for each of the three tasks.

The grading system in effect for all classrooms assigned points (usually on a 100-point scale) or grades (on the traditional letter scale) for correct and accurate performance on classroom tasks. All the teachers involved used grading procedures that separated behavioral compliance and effort from actual performance by providing separate marks for attendance and class participation. These latter marks were not included in the summary measures of classroom performance. The distribution of grades for all classrooms followed an individualistic, criterion-referenced system that allowed all students the possibility of receiving an $\mathrm{A}$ or a 100 on an assignment (i.e., none of the teachers used an explicit "grading curve" to assign grades). Semester grades also were obtained. We collected the first semester overall grade in the course, administered the MSLQ, and then collected second semester grades. All five performance scores (seatwork, tests/ quizzes, essays/reports, and the two semester grades) were standardized (converted to $T$ scores) within each classroom before data analysis.

\section{Results}

The first question of the study concerned the relations between the motivational and self-regulated learning components; the results were generally as expected. Table 1 displays the zero-order correlations and summary statistics for the motivational and self-regulated learning variables. As predicted, higher levels of self-efficacy $(r=.33)$ and intrinsic value $(r=.63$ ) were correlated with higher levels of cognitive strategy use. Test anxiety was not associated with cognitive strategy use. Paralleling these findings for cognitive strategy use, higher levels of self-efficacy $(r=.44)$ and intrinsic value $(r=.73)$ were correlated with higher levels of self-regulation. Test anxiety was negatively correlated with self-regulation ( $r$ $=-.13$ ), albeit not at the .05 significance level. In addition, simple polynomial regressions with second- and third-order terms (Neter, Wasserman, \& Kutner, 1985) for test anxiety revealed no curvilinear relations between test anxiety and the cognitive-strategy-use or self-regulation variables.

The second research question concerned the potential interactions between the motivational variables on the two cognitive scales. The two cognitive scales were correlated with each other and were used as dependent variables in a multivariate analysis of covariance with prior achievement (first semester grade) as a covariate (MANCOVA). In order to test for interactions, the three motivational variables were dichotomized by median splits, forming three low/high categorical variables to be used as independent variables in the MANCOVA. Before the MANCOVA was run, gender differences were exam-

Table 1

Summary Statistics and Zero-Order Correlations for Motivation and Self-Regulated Learning Variables

\begin{tabular}{lrrrrr}
\hline \multicolumn{1}{c}{ Variable } & 1 & 2 & 3 & 4 & 5 \\
\hline 1. Intrinsic value & - & & & & \\
2. Self-efficacy & $.48^{*}$ & - & & & \\
3. Test anxiety & -.01 & $-.34^{*}$ & - & & \\
4. Strategy use & $.63^{*}$ & $.33^{*}$ & .04 & - & \\
5. Self-regulation & $.73^{*}$ & $.44^{*}$ & -.13 & $.83^{*}$ & - \\
& & & & & \\
$M$ & 5.44 & 5.47 & 3.58 & 5.20 & 5.03 \\
$S D$ & 0.89 & 1.00 & 1.67 & 0.77 & 0.83 \\
\hline
\end{tabular}

Note. $N=173$.

$* p<.001$. 
ined in preliminary analyses. Boys and girls did not differ on any of the classroom performance variables or on the two cognitive variables and intrinsic value. There were, however, gender differences in self-efficacy; boys $(M=5.78)$ rated themselves more efficacious than did girls $(M=5.23), t(171)$ $=3.53, p<.0005$, and boys $(M=3.19)$ felt less test anxious than did girls $(M=3.86), t(171)=2.67, p<.008$. Preliminary multivariate analyses of variance (MANOVAs) revealed no main effects of gender on the two cognitive variables or interactive effects with the three motivational variables. Consequently, gender was excluded from the MANCOVA. Two assumptions for the MANCOVA were checked before the analysis proceeded. The tests for homogeneity of regression coefficients of the covariate for different levels of the motivational variables were not significant, suggesting that a common regression coefficient was appropriate for the covariance portion of the analysis (Neter, Wasserman, \& Kutner, 1985). In addition, Box's $M$ test for homogeneity of covariance matrices was not significant; this provided assurance that a crucial assumption of MANOVA was met (Stevens, 1986).

The results from the MANCOVA revealed a significant multivariate test for the covariate of prior achievement, Hotelling's statistic $=.05, \mathrm{~S}=1, \mathrm{M}=0, \mathrm{~N}=801 / 2, F(2,163)=$ $3.97, p<.02$. The univariate tests showed that prior achievement was a significant predictor of self-regulation, $r=.17$, $F(1,164)=4.80, p<.03, M S_{\mathrm{e}}=0.38$, but not cognitive strategy use, $r=.04, F(1,164)=.27, p<.61, M S_{\mathrm{e}}=0.43$. Students who were achieving high grades were more likely to report using self-regulatory strategies than were low-achieving students, although there were no differences in their cognitive strategy use. There were two main effects of the motivational variables. The multivariate test for self-efficacy was significant, Hotelling's statistic $=.05, \mathrm{~S}=1, \mathrm{M}=0, \mathrm{~N}=801 / 2$, $F(2,163)=4.07, p<.02$. The univariate tests were both significant also. Students high in self-efficacy were more likely to report use of cognitive strategies, adjusted $M=5.41, F(1$, $164)=4.24, p<.04, M S_{e}=0.43$, and self-regulatory strategies, adjusted $M=5.31, F(1,164)=8.16, p<.005, M S_{\mathrm{e}}=$ 0.38 , than students low in self-efficacy (cognitive strategy adjusted $M=4.97$; self-regulation adjusted $M=4.74$ ). The other main effect involved intrinsic value with a significant multivariate test, Hotelling's statistic $=.42, \mathrm{~S}=1, \mathrm{M}=0, \mathrm{~N}$ $=801 / 2, F(2,163)=34.25, p<.0001$. The two univariate tests were also significant. Students high in intrinsic value were more likely to use cognitive strategies, adjusted $M=$ $5.58, F(1,164)=45.93, p<.0001, M S_{\mathrm{e}}=0.43$, and to be self-regulating, adjusted $M=5.49, F(1,164)=68.40, p<$ $.0001, M S_{\mathrm{e}}=0.38$, than students low in intrinsic value (cognitive strategy adjusted $M=4.80$, self-regulation adjusted $M=4.56$ ). The main effect for test anxiety was not significant at the multivariate or univariate level, nor were any of the interaction terms for the motivational variables significant at the multivariate or univariate level.

The third research question concerned how the motivational and cognitive variables were related to student performance. Table 2 displays the zero-order correlations for the motivational, cognitive, and performance variables. As predicted, higher levels of intrinsic value and self-efficacy were associated with higher levels of student achievement across all types of tasks (see Table 2). Higher levels of test anxiety were only significantly related to lower levels of performance on exams and quizzes $(r=-.21)$ as well as grades at times one $(r=-.24)$ and two $(r=-.23)$, but not for seatwork performance or essays and lab reports. In addition, higher levels of cognitive strategy use and self-regulation were associated with higher levels of achievement on all assignments, with the exception of seatwork performance and cognitive strategy use (see Table 2). All the performance measures were significantly and positively correlated with each other, suggesting that performance levels were relatively stable over time. Because first and second semester grades were highly correlated $(r=.77)$, one measure, the average grade for the two semesters, was used in the analyses. A MANOVA with the four performance measures as dependent variables, following the logic of the previous analysis for the two cognitive variables, was ruled out because the test (Box's $M$ ) for homogeneity of covariance matrices was significant. Accordingly, to examine the independent relations between the motivational and cognitive variables on student performance, four separate regression analyses were run with the three motivational and two cognitive variables as predictors of student performance on seatwork, exams/quizzes, essays/reports, and average grade for the course.

Regression analysis of seatwork performance $\left(r^{2}=.10\right)$ revealed that self-regulation was positively related to seatwork performance (partial $r=.18, p<.02$ ). In addition, somewhat surprisingly, cognitive strategy use was negatively related to seatwork performance (partial $r=-.18, p<.02$ ). The three

Table 2

Zero-Order Correlations Between Motivation and Self-Regulated Learning Variables and Performance

\begin{tabular}{|c|c|c|c|c|c|}
\hline Variable & $\begin{array}{c}\text { Grade } \\
1\end{array}$ & $\begin{array}{l}\text { Seat- } \\
\text { work }\end{array}$ & $\begin{array}{l}\text { Exams/ } \\
\text { Quizzes }\end{array}$ & $\begin{array}{l}\text { Essays/ } \\
\text { Reports }\end{array}$ & $\begin{array}{c}\text { Grade } \\
2\end{array}$ \\
\hline \multicolumn{6}{|l|}{ Motivation components } \\
\hline Intrinsic value & $.25^{* *}$ & $.21^{* *}$ & $.20^{* *}$ & $.27 * *$ & $.30^{* * *}$ \\
\hline Self-efficacy & $.34^{* * *}$ & $.19^{*}$ & $.24^{* *}$ & $.25^{* *}$ & $.36^{* * *}$ \\
\hline Test anxiety & $-.24^{* *}$ & -.14 & $-.21 * *$ & -.14 & $-.23^{* *}$ \\
\hline \multicolumn{6}{|c|}{ Self-regulated learning components } \\
\hline Strategy use & $.18^{*}$ & .07 & $.20^{* *}$ & $.19^{*}$ & $.20^{* *}$ \\
\hline Self-regulation & $.32^{* * * *}$ & $.22^{* *}$ & $.28^{* *}$ & $.36 * * *$ & $.36^{* * * *}$ \\
\hline
\end{tabular}

Note. $N=173$.

${ }^{*} p<.05 .^{* *} p<.01 .^{* * *} p<.001$. 
motivational variables were not significantly related to seatwork performance when included in the regression analyses with the two cognitive variables. For exams/quizzes $\left(r^{2}=\right.$ .12 ), test anxiety was negatively related to performance (partial $r=-.19, p<.02$ ) and self-regulation was positively related (partial $r=.26, p<.0005$ ). Cognitive strategy use, self-efficacy, and intrinsic value were not significant predictors of exam performance in comparison with test anxiety and self-regulation. The results for essays/reports $\left(r^{2}=.17\right)$ displayed a pattern similar to that revealed by the results for seatwork. None of the motivational variables was significant, but self-regulation (partial $r=.22, p<.0004$ ) was positively related to performance and cognitive strategy use negatively related (partial $r=-.17, p<.02$ ). Regression analysis on average grade $\left(r^{2}=.22\right)$ revealed that the significant predictors were self-efficacy (partial $r=.18, p<.02$ ) and self-regulation (partial $r=.22, p<.005$ ). Analyses of variance (ANOVAs) with the motivational and cognitive variables as independent dichotomous variables did not reveal any two- or three-way interactions on the four student performance outcome measures.

The findings that cognitive strategy use, which had a significant positive zero-order correlation with most of the performance measures (see Table 2), had negative partial correlations and betas with performance when self-regulation was included in the regression equation suggested a suppressor effect was operating. Further examination of the partials, betas, and zero-order correlations between cognitive strategy use, selfregulation, and the performance measures following the procedures to detect suppressor variables (e.g., Conger, 1974; Tzelgov \& Stern, 1978) suggested that cognitive strategy use could be classified as a negative suppressor variable. Cognitive strategy use and self-regulation were highly correlated with each other $(r=.83)$ and self-regulation was a better predictor of performance. When the variance in performance due to self-regulation was accounted for, the remaining variance correlated with cognitive strategy use revealed a negative relation. This suggested that some students who reported that they often used cognitive strategies also reported infrequent use of self-regulatory strategies. Examination of the actual number of students who showed this pattern revealed that 14 students ( $8 \%$ of the sample) could be classified as being in the top third on cognitive strategy use and the bottom third in self-regulation. Simple two-way ANOvas did not reveal a significant interaction between cognitive strategy use (three levels) and self-regulation (three levels), but the group low in self-regulation and high in cognitive strategy use consistently had means on the performance measures well below the 50.0 mean for the total sample (seatwork $M=45.6$, exam $M=$ 47.3 , essay $M=42.0$, average grade $M=43.2$ ) or the other group means, which were all above 46.2 .

\section{Discussion}

The results provide an empirical base for the specification and elaboration of the theoretical linkages between individual differences in students' motivational orientation and their cognitive engagement and self-regulation in classroom settings (cf., Corno \& Mandinach, 1983; Snow, 1989; Weinert, 1987). The motivational components were linked in important ways to student cognitive engagement and academic performance in the classroom. Self-efficacy was positively related to student cognitive engagement and performance. Students who believed they were capable were more likely to report use of cognitive strategies, to be more self-regulating in terms of reporting more use of metacognitive strategies, and to persist more often at difficult or uninteresting academic tasks. These relations were independent of and did not interact with prior achievement levels or intrinsic value and test anxiety. Selfefficacy, however, was not significantly related to performance on seatwork, exams, or essays when the cognitive engagement variables were included in the regression analyses. These findings suggest that self-efficacy plays a facilitative role in relation to cognitive engagement as suggested by Schunk (1985), but that the cognitive engagement variables are more directly tied to actual performance. This implies that teaching students about different cognitive and self-regulatory strategies may be more important for improving actual performance on classroom academic tasks, but that improving students' self-efficacy beliefs may lead to more use of these cognitive strategies (cf., Borkowski, Weyhing, \& Carr, 1988; Garner \& Alexander, 1989; Schunk, 1985).

Intrinsic value was very strongly related to use of cognitive strategies and self-regulation, independent of initial performance levels or self-efficacy and test anxiety. Students who were motivated to learn the material (not just get good grades) and believed that their school work was interesting and important were more cognitively engaged in trying to learn and comprehend the material. In addition, these students were more likely to be self-regulating and to report that they persisted on their academic work. It is important to note that intrinsic value did not have a significant direct relation to student performance in any of the regressions that included cognitive strategy use or self-regulation. The cognitive variables, selfregulation in particular, were better predictors of actual academic performance. This finding parallels the work of Eccles (1983), who found that value components did not have a direct influence on student achievement in math but were closely tied to students' choice of future math courses. In a similar fashion, our data suggest that intrinsic value is an important component of students' "choice" about becoming cognitively engaged in their classroom academic work. Although our correlational data cannot address causality, it appears that the students who choose to become cognitively engaged and self-regulating are those who are interested in and value the tasks they work on in their classrooms. Accordingly, students' intrinsic value and motivation to learn is an important component to be considered in our models of how students come to use different cognitive strategies and become self-regulating learners (cf., Meece et al., 1988; Nolen, 1988). In addition, the results imply that it is important for teachers to socialize students' intrinsic value for schoolwork (cf., Brophy, 1983; Corno \& Rohrkemper, 1985), not because it will necessarily lead to higher grades or scores on academic assignments or standardized achievement tests directly, but because it may lead to more cognitive engagement in the day-to-day work of the classroom. 
Test anxiety was not significantly related in a linear or nonlinear fashion to use of cognitive strategies or self-regulation, but it was negatively related to self-efficacy and performance on exams and quizzes. The linear relation between test anxiety and self-regulation, although not significant, was in the expected direction; high-anxious students reported less self-regulation and persistence (cf., Hill \& Wigfield, 1984). The direct relation between test anxiety and exam performance and the lack of any interactions between test anxiety and self-regulation suggest that, for this sample of students, the effects of test anxiety are related to retrieval problems at the time of testing rather than to lack of effective cognitive strategies for encoding or organizing course material. This interpretation is in line with cognitive models of test anxiety (e.g., Benjamin, McKeachie, \& Lin, 1987; Tobias, 1985) that propose that for some test-anxious students who actually have adequate cognitive skills, test anxiety during exams engenders worry about their capabilities that interferes with effective performance. This interpretation is further supported by the negative relation between self-efficacy and test anxiety in this sample.

The findings for the cognitive variables provide ecologically valid data on academic performance on actual classroom tasks in support of a general model of self-regulated learning. Students who were more cognitively engaged in trying to learn by memorizing, organizing, and transforming classroom material through the use of rehearsal, elaboration, and organizational cognitive strategies performed better than students who tended not to use these strategies (Corno and Mandinach, 1983; Weinstein \& Mayer, 1986). More important, the finding that self-regulation was the best predictor of academic performance on all the outcome measures suggests that the use of self-regulating strategies, such as comprehension monitoring, goal setting, planning, and effort management and persistence, is essential for academic performance on different types of actual classroom tasks (Corno, 1986; Zimmerman \& Pons, 1986, 1988). Self-regulation was highly correlated with cognitive strategy use, yet the two constructs can be distinguished conceptually, and when both were entered as predictors of academic performance, cognitive strategy use had a negative relation to performance. This apparent negative suppressor effect of cognitive strategy use on academic performance suggests that cognitive strategy use without the concommitant use of self-regulatory strategies is not conducive to academic performance. This interpretation is in line with the research on metacognition and self-regulation that suggests that students must be able to understand not only the "what" of cognitive strategies, but also how and when to use strategies appropriately (cf., Brown et al., 1983; Paris et al., 1983; Pressley, 1986).

There are several limitations to these findings, however. First, all the student motivation and cognitive components were measured with a self-report instrument. Self-reports can be used effectively to measure student perceptions of motivation and cognitive engagement (e.g., Ames \& Archer, 1988; Meece et al., 1988; Weinstein et al., 1987), but the results need to be replicated with other measures, such as thinkaloud protocols, stimulated recall procedures, structured interviews, or behavioral measures (cf., Garner \& Alexander,
1989; Zimmerman \& Pons, 1986). The negative suppressor effect of cognitive strategy use may merely reflect methodological problems involved in using a self-report instrument for assessing cognitive strategy use with junior high school students. In addition, it seems clear from the moderate levels of variance explained on the performance measures that there are other factors implicated in student academic performance in the classroom. For example, seatwork performance may reflect both students' willingness to comply with classroom norms about work completion and teachers' grading practices with respect to student behavioral compliance (e.g., Blumenfeld, Pintrich, \& Hamilton, 1987; Hamilton, Blumenfeld, \& Kunstler, 1987). Student knowledge factors, including the amount and organization of prior knowledge, were not assessed, yet they relate to student academic performance and potentially interact with cognitive and metacognitive strategy use (Alexander \& Judy, 1988). Finally, these relationships may vary by classroom task and context variables. Different relationships between student motivational and self-regulated learning components and academic performance may be obtained with younger or older students or in different classroom settings (e.g., cooperative-competitive or ability grouped-ungrouped) that have different arrays of classroom tasks (e.g., Ames \& Archer, 1988; Doyle, 1983). Clearly, more ecologically valid classroom research is needed on the multivariate relationships between student academic performance and student motivational orientation and self-regulated learning as well as social cognitive and knowledge factors in different classroom contexts.

In summary, the results provide ecologically valid empirical evidence for the importance of considering both motivational and self-regulated learning components in our models of classroom academic performance. Student involvement in self-regulated learning is closely tied to students' efficacy beliefs about their capability to perform classroom tasks and to their beliefs that these classroom tasks are interesting and worth learning. At the same time, these motivational beliefs are not sufficient for successful academic performance; selfregulated learning components seem to be more directly implicated in performance. Students need to have both the "will" and the "skill" to be successful in classrooms (cf., Blumenfeld, Pintrich, Meece, \& Wessels, 1982; Paris et al., 1983; Pintrich, 1989), and we need to integrate these components in our models of classroom learning.

\section{References}

Alexander, P., \& Judy, J. (1988). The interaction of domain-specific and strategic knowledge in academic performance. Review of Educational Research, 58, 375-404.

Ames, C., \& Archer, J. (1988). Achievement goals in the classroom: Student learning strategies and motivation processes. Journal of Educational Psychology, 80, 260-267.

Benjamin, M., McKeachie, W. J., Lin, Y. G., \& Holinger, D. P. (1981). Test anxiety: Deficits in information processing. Journal of Educational Psychology, 73, 816-824.

Benjamin, M., McKeachie, W. J., \& Lin, Y. G. (1987). Two types of test-anxious students: Support for an information processing model. Journal of Educational Psychology, 79, 131-136.

Blumenfeld, P. C., Pintrich, P. R., \& Hamilton, V. L. (1987). Teacher 
talk and students' reasoning about morals, conventions, and achievement. Child Development, 58, 1389-1401.

Blumenfeld, P. C., Pintrich, P. R., Meece, J., \& Wessels, K. (1982). The role and formation of self-perceptions of ability in elementary classrooms. Elementary School Journal, 82, 401-420.

Borkowski, J., Weyhing, R., \& Carr, M. (1988). Effects of attributional retraining on strategy-based reading comprehension in learningdisabled students. Journal of Educational Psychology, 80, 46-53.

Brophy, J. (1983). Conceptualizing student motivation. Educational Psychologist, 18, 200-215.

Brown, A. L., Bransford, J. D., Campione, J. C., \& Ferrara, R. A. (1983). Learning, remembering and understanding. In J. Flavell \& E. Markman (Eds.), Handbook of child psychology: Vol. 3. Cognitive Development (pp. 77-166). New York: Wiley.

Calfee, R. (1985). Home grown tests have virtues, too. Update: The study of Stanford and the schools, 2, 3.

Conger, A. J. (1974). A revised definition for suppressor variables: A guide to their identification and interpretation. Educational and Psychological Measurement, 34, 35-46.

Corno, L. (1986). The metacognitive control components of selfregulated learning. Contemporary Educational Psychology, 11, 333-346.

Corno, L., \& Mandinach, E. (1983). The role of cognitive engagement in classroom learning and motivation. Educational Psychologist, $18,88-100$.

Corno, L., \& Rohrkemper, M. (1985). The intrinsic motivation to learn in classrooms. In C. Ames \& R. Ames (Eds.), Research on motivation: Vol. 2. The classroom milieu (pp. 53-90). New York: Academic Press.

Corno, L., \& Snow, R. (1986). Adapting teaching to individual differences among learners. In M. Wittrock (Ed.), Handbook of research on teaching (pp. 605-629). New York: Macmillan.

Culler, R. E., \& Holahan, C. J. (1980). Test anxiety and academic performance: The effects of study related behaviors. Journal of Educational Psychology, 72, 16-20.

Doyle, W. (1983). Academic work. Review of Educational Research, $53,159-200$.

Dweck, C., \& Elliott, E. (1983). Achievement motivation. In E. M. Heatherington (Ed.), Handbook of child psychology: Vol. 4. Socialization, personality, and social development. (pp. 643-691). New York: Wiley.

Eccles, J. (1983). Expectancies, values and academic behaviors. In J. T. Spence (Ed.), Achievement and achievement motives (pp. 75146). San Francisco: Freeman.

Fincham, F., \& Cain, K. (1986). Learned helplessness in humans: A developmental analysis. Developmental Review, 6, 25-86.

Garner, R., \& Alexander, P. (1989). Metacognition: Answered and unanswered questions. Educational Psychologist, 24, 143-158.

Hamilton, V. L., Blumenfeld, P. C., \& Kunstler, R. H. (1988). A question of standards: Attributions of blame and credit for classroom acts. Journal of Personality and Social Psychology, 54, 3448.

Harter, S. (1981). A new self-report scale of intrinsic versus extrinsic orientation in the classroom: Motivational and informational components. Developmental Psychology, 17, 300-312.

Hill, K., \& Wigfield, A. (1984). Test anxiety: A major educational problem and what can be done about it. Elementary School Journal, 85, 105-126.

Liebert, R., \& Morris, L. (1967). Cognitive and emotional components of test anxiety: A distinction and some initial data. Psychological Reports, 29, 975-978.

Malone, T. W. (1981). Toward a theory of intrinsically motivating instruction. Cognitive Science, 4, 333-369.
Meece, J., Blumenfeld, P., \& Hoyle, R. (1988). Students' goal orientations and cognitive engagement in classroom activities. Journal of Educational Psychology, 80, 514-523.

Neter, J., Wasserman, W., \& Kutner, M. (1985). Applied linear statistical models. Homewood, IL: Richard D. Irwin.

Nicholls, J. (1976). When a scale measures more than its name denotes: The case of the Test Anxiety Scale for Children. Journal of Consulting and Clinical Psychology, 44, 976-985.

Nolen, S. (1988). Reasons for studying: Motivational orientations and study strategies. Cognition and Instruction, 5, 269-287.

Paris, S. G., Lipson, M. Y., \& Wixson, K. (1983). Becoming a strategic reader. Contemporary Educational Psychology, 8, 293-316.

Paris, S. G., \& Oka, E. (1986). Children's reading strategies, metacognition and motivation. Developmental Review, 6, 25-86.

Pintrich, P. R. (1988). A process-oriented view of student motivation and cognition. In J. S. Stark \& L. Mets (Eds.), Improving teaching and learning through research. New directions for institutional research, 57 (pp. 55-70). San Francisco: Jossey-Bass.

Pintrich, P. R. (1989). The dynamic interplay of student motivation and cognition in the college classroom. In C. Ames \& M. Maehr (Eds.), Advances in motivation and achievement: Vol. 6. Motivation enhancing environments (pp. 117-160). Greenwich, CT: JAI Press.

Pintrich, P. R., Cross, D. R., Kozma, R. B., \& McKeachie, W. J. (1986). Instructional psychology. Annual Review of Psychology, 37, 611-651.

Pressley, M. (1986). The relevance of the good strategy user model to the teaching of mathematics. Educational Psychologist, 21, 139161.

Schunk, D. (1981). Modeling and attributional effects on children's achievement: A self-efficacy analysis. Journal of Educational Psychology, 73, 93-105.

Schunk, D. (1985). Self-efficacy and school learning. Psychology in the Schools, 22, 208-223.

Snow, R. (1989). Aptitude-treatment interaction as a framework for research on individual differences in learning. In P. Ackerman, $R$. Sternberg, \& R. Glaser (Eds.), Learning and individual differences (pp. 13-59). New York: Freeman.

Stevens, J. (1986). Applied multivariate statistics for the social sciences. Hillsdale, NJ: Erlbaum.

Stiggins, R., \& Bridgeford, N. (1985). The ecology of classroom assessment. Journal of Educational Measurement, 22, 271-286.

Tobias, S. (1985). Test anxiety: Interference, defective skills, and cognitive capacity. Educational Psychologist, 20, 135-142.

Tzelgov, J., \& Stern, I. (1978). Relationships between variables in three variable linear regression and the concept of suppressor. Educational and Psychological Measurement, 38, 325-335.

Weinert, F. (1987). Metacognition and motivation as determinants of effective learning and understanding. In F. Weinert \& R. Kluwe (Eds.), Metacognition, motivation, and understanding (pp. 1-15). Hillsdale, NJ: Erlbaum.

Weinstein, C. E., \& Mayer, R. E. (1986). The teaching of learning strategies. In M. Wittrock (Ed.), Handbook of research on teaching (pp. 315-327). New York: Macmillan.

Weinstein, C. E., Schulte, A., \& Palmer, D. R. (1987). The Learning and Study Strategies Inventory. Clearwater, FL: H \& H Publishing.

Wigfield, A., \& Eccles, J. (1989). Test anxiety in elementary and secondary school students. Educational Psychologist, 24, 159-183.

Zimmerman, B., \& Pons, M. (1986). Development of a structured interview for assessing student use of self-regulated learning strategies. American Educational Research Journal, 23, 614-628.

Zimmerman, B., \& Pons, M. (1988). Construct validation of a strategy model of student self-regulated learning. Journal of Educational Psychology, 80, 284-290. 


\section{Appendix}

The following scales and items represent the Motivated Strategies for Learning Questionnaire (MSLQ) that was used in this study to measure students' motivational beliefs and self-regulated learning. The numbers next to the items reflect the item's actual position on the questionnaire. Items marked $\left({ }^{*} R\right)$ were reflected before scale construction. There were 56 items on the questionnaire, but only 44 were used in this study to form the following five scales.

\section{Motivational Beliefs}

\section{A. Self-Efficacy}

2. Compared with other students in this class I expect to do well.

7. I'm certain I can understand the ideas taught in this course.

10. I expect to do very well in this class.

11. Compared with others in this class, I think I'm a good student.

13. I am sure $I$ can do an excellent job on the problems and tasks assigned for this class.

15. I think I will receive a good grade in this class.

20. My study skills are excellent compared with others in this class.

22. Compared with other students in this class I think I know a great deal about the subject.

23. I know that I will be able to learn the material for this class.

\section{B. Intrinsic Value}

1. I prefer class work that is challenging so I can learn new things.

5. It is important for me to learn what is being taught in this class.

6. I like what I am learning in this class.

9. I think I will be able to use what I learn in this class in other classes.

12. I often choose paper topics I will learn something from even if they require more work.

17. Even when I do poorly on a test I try to learn from my mistakes.

18. I think that what I am learning in this class is useful for me to know.

21. I think that what we are learning in this class is interesting.

25. Understanding this subject is important to me.

\section{Test Anxiety}

3. I am so nervous during a test that I cannot remember facts I have learned.

14. I have an uneasy, upset feeling when I take a test.

24. I worry a great deal about tests.

27. When I take a test I think about how poorly I am doing.

\section{Self-Regulated Learning Strategies}

\section{Cognitive Strategy Use}

30. When I study for a test, I try to put together the information from class and from the book.

31. When I do homework, I try to remember what the teacher said in class so I can answer the questions correctly.

33. It is hard for me to decide what the main ideas are in what I read. $\left({ }^{*} R\right)$

35. When I study I put important ideas into my own words.

36. I always try to understand what the teacher is saying even if it doesn't make sense.

38. When I study for a test I try to remember as many facts as I can.

39. When studying, I copy my notes over to help me remember material.

42. When I study for a test I practice saying the important facts over and over to myself.

44. I use what I have learned from old homework assignments and the textbook to do new assignments.

47. When I am studying a topic, I try to make everything fit together.

53. When I read material for this class, I say the words over and over to myself to help me remember.

54. I outline the chapters in my book to help me study.

56. When reading I try to connect the things I am reading about with what I already know.

\section{E. Self-Regulation}

32. I ask myself questions to make sure I know the material I have been studying.

34. When work is hard I either give up or study only the easy parts. $\left({ }^{*} R\right)$

40. I work on practice exercises and answer end of chapter questions even when I don't have to.

41. Even when study materials are dull and uninteresting, I keep working until I finish.

43. Before I begin studying I think about the things I will need to do to learn.

45. I often find that I have been reading for class but don't know what it is all about. $\left({ }^{*} R\right)$

46. I find that when the teacher is talking I think of other things and don't really listen to what is being said. $\left({ }^{*} R\right)$

52. When I'm reading I stop once in a while and go over what I have read.

55. I work hard to get a good grade even when I don't like a class.

Received July 13, 1988

Revision received July 7, 1989

Accepted September 12, 1989 